\title{
Level of Knowledge, Practice and Attitudes of Taking Anthropometric Measurements for Nutritional Assessments Among Nurses
}

\author{
Wijedasa, $\mathrm{H}$. \\ hiranga.w@sliit.lk \\ Department of Nursing, Faculty of Humanities and Sciences, SLIIT, Malabe, Sri Lanka
}

\begin{abstract}
The nutritional care of patients is one of the primary responsibilities of the nurses in any hospital. Nursing ability to early detect nutritional failure is the key factor for minimizing impurities in practice and attaining nutritional goals. The objective of this study is therefore to determine the level of knowledge, practice, and attitudes of taking anthropometric measurements for nutritional assessments by registered staff nurses. A descriptive cross-sectional study was done using a random sample of 125 nurses at a teaching hospital in the Western Province. Self-administered questionnaire with both open and close ended questions were used to gather information. A scoring method was introduced to assess the knowledge of the nurses based on answers for the questions. Majority (88\%) of the nurses are females and $47 \%$ are less than 30 years. Results found that the level of knowledge of getting measurements by the nurses can be ranked as good $(52.8 \%)>$ average $>(38.4 \%)$ and poor $>(8.8 \%)$ irrespective of demographic factors of the nurses. Level of knowledge is significantly associated only with the educational level. The percentage of having good knowledge among those having B.Sc. degree is significantly higher than that of having those diploma qualifications either from government or private organization. The two main constraints to take anthropometric measurements are the lack of time and lack of resources. There is a significant association between the level of confidence and the type of measurement. The percentage of confidence for weight measurement (93.5\%) is significantly higher than the percentage of confidence for taking other measurements. Almost all nurses (98.4\%) are not confident in measuring hip circumference. The measure of waist, hip and head circumference are hardly considered as a measure of anthropometric measurements.
\end{abstract}

Keywords: Attitude, Staff Nurses, Anthropometric measurements, Nutritional Assessment

\section{Introduction}

In Sri Lanka, thirty percent (30\%) of population is overweight and fifteen percent $(15 \%)$ of population is underweight (World Health Organization, 2015). Overweight and obesity are significantly associated with diabetes, high blood pressure, high cholesterol, asthma, arthritis, and poor health status among US adults (Mokdad et al., 2001). Overweight and obesity are common amongst teenagers/ adolescents and young adults of the South Asian region (Jayawardena et al., 2017).

Nutritional assessment consists of four major aspectsincludingAnthropometric assessments, Biochemical Analysis, Clinical evaluation and Dietary history. Anthropometry includes 
measurements of body weight, height, abdominal circumference, calf circumference, mid arm muscle circumference, and subscapular skinfold (Fuchs \& Pierre, 2014). Anthropometric assessments are best to perform in the hospital setup considering the advantages reported by Gibson (1998): the procedures used are safe to humans and are non-invasive, it is applicable to large sample groups, equipment required for the technique is inexpensive, portable and durable, and even the measurements can be performed by relatively unskilled personnel.

The measurement of body weight and height to calculate Body Mass Index (BMI) is a major part of various nutritional screening and assessment tools (Green \& Watson, 2005). Health care professionals should have good skills to perform nutritional assessments. Without recording weight and height, it would be difficult to monitor the patient's response to nutritional interventions (Campbell et al., 2002). Registered Nurses have close and continuous contact with patients, they are in an ideal position to screen or assess for malnutrition (Lennard-Jones et al., 1995) because self-reported weight and height in adults are not accurate (Krul et al., 2010 \& Shiely et al., 2013) and inconsistencies in recording body weight can have a negative impact on patient care (Clarkson, 2012). Studies demonstrate that lack of appropriate material, knowledge and time are the most prominent factors limiting the systematic measurement of body weight and height in hospitalized patients (Bavelaar et al., 2008 \& Raja et al., 2008).

Indicators of body weight status are determinantsofoverweight orobesity including body mass index (BMI), waist circumference (WC) and waist-hip ratio (WHR) (Laquatra, 2004). WHO (2015) recommends Body Mass Index $\left(\mathrm{BMI}=\mathrm{Wt} / \mathrm{Ht}^{-2}\right)$ as the primary measure of obesity and defines BMI as "a crude population measure of obesity", “a person's weight (in kilograms) divided by the square of his or her height (in meters)". Quetelet's Index, weight $(\mathrm{kg}) /$ height $^{2}\left(\mathrm{~m}^{2}\right)$, is most often used for adults while Ponderal's Index, height (m)/ weight $\left(\mathrm{kg}^{-3}\right)$ for children (Lees et al., 1995). Overweight and obesity are defined, respectively, as BMI values exceeding 25 $\mathrm{kg} / \mathrm{m}^{2}$ and $30 \mathrm{~kg} / \mathrm{m}^{2}$ (Whitney et al., 2006). Katulanda et al. (2010) proposed that the BMI of $21.5 \mathrm{~kg} / \mathrm{m}^{2}$ as the cut-off level for diagnosing overweight in Sri Lankan adults. People who carry excess fat centrally (within the abdominal cavity) are more likely to suffer from the consequences of being overweight (Zhu et al., 2002). Fat distribution is measured by Waist Circumference (WC) and Waist to Height Ratio (WHR) as BMI does not give information about the total fat or how fat is distributed in the body (Hammond, 2004).

Batsis et al. (2014) found that elevated WC is associated with lower quality of life, a decline in physical function and a slightly higher risk of disability over time in older adults. As indicated in Anthropometry procedures manual (National Health and Nutrition Examination Survey, 2004) in order to take correct measurement of WC, it is necessary to have the patient stand and hold the examination gown above the waist, lowering the pants and underclothing. Reading of the measuring tape over the horizontal line just above the uppermost lateral border of the ilium should be taken at the end of a normal respiration (National Health and Nutrition 
Examination Survey, 2004). A cut-off value of $75 \mathrm{~cm}$ for WC is proposed for both men and women based on the findings of Katulanda et al. (2010). Waist to Hip Ratio is also a simple and effective anthropometric index to identify obesity associated metabolic risks among Sri Lankan adults (Jayawardana et al., 2012). WHR cut-off values proposed are 0.85 for women and 0.90 for men. Calculation of WHR needs two relatively difficult measurements and hence can be subject to more errors (Katulanda et al., 2010).

Convincing evidence indicates that $\mathrm{WC}$ and WHR are strongly associated with many noncommunicable diseases declining quality of life and physical activity levels (Batsis et al., 2014 and Chapala et al., 2015).

This topic yields few scholarly articles similar to this study, when searched in the World Wide Web. Still, a thorough search would not show any results regarding studies done in Sri Lanka. On view of the above explanation led to the objective of this study to explore and describe the knowledge, practice and attitudes of taking anthropometric measurements for nutritional assessments among nurses.

\section{Materials and Methods}

This study was conducted at a teaching hospital in the Western Province where staff nurses from both private sector and government sector were working together at the time of data collection. The group of nurses in this hospital have different educational levels as well as different years of experience in nursing service. Further, nursing degree holders from different state universities are also working in this hospital.

\section{Sample size}

The population of this study is the nurses in the selected hospital and thus the population size is 139. A sample size was decided at the $5 \%$ margin of error with $95 \%$ confidence. When the population size is known $(\mathrm{N})$ the sample size (n), at the margin of error of 5\% with $95 \%$ confidence interval is given by (1) (Abramson, 1991).

$n=\frac{N * X}{(X+N-1)}, \quad$ where $X=\frac{\left(1.96^{2}\right)^{*}\left(0.5^{2}\right)}{(0.5)^{2}}=384$

Accordingly, it was found that sample size, $\mathrm{n}=102$. However, a sample of 125 was selected. ( need to say why this decision $)^{* * * *}$ ) The nurses were selected within the different units in the hospital where nurses do work (Table 1). The nurses who were in maternity leave during the data collection period who cannot understand Sinhala or English medium and who work as part time employees were excluded from the sample.

\section{Table 1.}

\section{Distribution of sample}

\begin{tabular}{lc}
\hline Unit & Sample Size \\
\hline Incentive Care Unit (ICU) & 20 \\
Medical ward & 13 \\
Theatre & 12 \\
ETU & 11 \\
Orthopaedic ward & 9 \\
Surgical ward & 9 \\
Gynaecology & 9 \\
OPD & 9 \\
Paying Section & 9 \\
Paediatric ward & 8 \\
Psychiatric Ward & 7 \\
Radiology Unit, Blood & 5 \\
Dialysis Unit & 4 \\
\hline
\end{tabular}




\section{Study instruments}

Self-administered semi structured questionnaire was used to determine the level of knowledge, practice and attitudes of taking anthropometric measurements for nutritional assessments. The self-administered questionnaire was pretested to determine the level of understanding and the time taken to complete all four sections. Ten (10) staff nurses working in private and government hospitals with similar characteristics were selected for the pertest. A few modifications were done in the questionnaire following the pertest. Anthropometric measurements were introduced at the beginning of the questionnaire. Maximum 15 minutes per participant is taken to complete the questionnaire.

Final questionnaire consisted of 50 questions/statements in four sections. Section A composed with 7 questions to obtain information on socio-demographic characteristics such as age, sex and marital status. It also sought information on years of clinical experience, educational qualifications and the working area in the hospital. Section $\mathrm{B}$ of the questionnaire consisted of 20 items with both statements and questions to assess the knowledge of nurses. Section C comprised of 10 items to assess the practice of nurses. Section D composed of 10 closed ended questions and the each correct answer scores 10 out of 100 to assess the attitudes of nurses.

\section{Study instruments}

Self-administered semi structured questionnaire was used to determine the level of knowledge, practice and attitudes of taking anthropometric measurements for nutritional assessments. The self-administered questionnaire was pretested to determine the level of understanding and the time taken to complete all four sections. Ten (10) staff nurses working in private and government hospitals with similar characteristics were selected for the pertest. A few modifications were done in the questionnaire following the pertest. Anthropometric measurements were introduced at the beginning of the questionnaire. Maximum 15 minutes per participant is taken to complete the questionnaire.

Final questionnaire consisted of 50 questions/statements in four sections. Section A composed with 7 questions to obtain information on socio-demographic characteristics such as age, sex and marital status. It also sought information on years of clinical experience, educational qualifications and the working area in the hospital. Section $\mathrm{B}$ of the questionnaire consisted of 20 items with both statements and questions to assess the knowledge of nurses. Section C comprised of 10 items to assess the practice of nurses. Section D composed of 10 closed ended questions and the each correct answer scores 10 out of 100 to assess the attitudes of nurses.

\section{Data collection}

Data collection was done by distributing the self-administered questionnaire. All the nurses were personally contacted directly or over the phone to explain the procedure by the investigator. After obtaining the written consent questionnaires were distributed among staff nurses in the quarters after finishing their shift duties and also at the time of leaving out of the hospital after finishing work or at any time convenient for them avoiding working hours. 


\section{Statistical analysis}

After collecting all completely filled questionnaires, data were entered the Statistical Package for the Social Science (SPSS) version 20.0 and basic exploratory analysis and chi-square analysis for 2-way frequency tables were carried out using SPSS.

The section B of the questionnaire was scored to measure the level of knowledge (Appendix 1). In this section each question was binary type. The correct answer to the question was scored one (1) and each wrong answer was scored zero (0). Score for the level of knowledge (SLK) is defined as,

$\mathrm{SLK}=\frac{\text { The number of correct answers for the Section B } * 100}{\text { total number of questions in Section B }}$

The total number of questions in Section B was 20. Thus, SLK is computed using (1)

$\mathrm{SLK}=\frac{\text { The number of correct answers for the Section B } * 100}{20}$
SLK can varies between zero and 100 and thus scores for knowledge level were categorized based on marks obtained. The level of knowledge was classified as, "poor", "average" and "good" if marks is between $0-45,45-75$ and above 75 respectively. The higher the score implies the greater the knowledge about taking of anthropometric measurements for nutritional assessments the participant has.

\section{Ethical considerations}

The verbal and written informed consent obtained from each participant prior to data collection after explaining the purpose of the study. Data collection was done out of their working place at the time of off duties. No risk was identified for the participants. Privacy and confidentiality of provided information/ data were ensured.

\section{Results and Discussion}

\section{Distribution of demographic variables and level of knowledge}

Distribution of sample size among the selected demographic variables is shown in Table 2.

Table 2.

Distribution of demographic variables of the participants

\begin{tabular}{llll}
\hline Characteristics & \multicolumn{1}{c}{$\begin{array}{l}\text { Number } \\
(\mathbf{N = 1 2 5 )}\end{array}$} & $\begin{array}{l}\text { Percentage } \\
\mathbf{( \% )}\end{array}$ \\
\hline \multirow{2}{*}{ Sex } & Male & 15 & $12.0 \%$ \\
\cline { 2 - 4 } & Female & 110 & $88.0 \%$ \\
\hline \multirow{2}{*}{ Marital Status } & Single & 64 & $51.2 \%$ \\
\cline { 2 - 4 } & Married & 61 & $48.8 \%$ \\
\hline
\end{tabular}


Table 2 (Continued)

\begin{tabular}{|c|c|c|c|}
\hline \multirow{4}{*}{ Age Group } & Less than 30 & 59 & $47.2 \%$ \\
\hline & 30-39 years & 45 & $36.0 \%$ \\
\hline & $40-49$ years & 14 & $11.2 \%$ \\
\hline & More than 50 & 07 & $5.6 \%$ \\
\hline \multirow{4}{*}{$\begin{array}{l}\text { Educational } \\
\text { qualifications }\end{array}$} & B.Sc. in Nursing & 20 & $16.0 \%$ \\
\hline & $\begin{array}{l}\text { Diploma in Nursing } \\
\text { (from government } \\
\text { NTS) }\end{array}$ & 41 & $32.8 \%$ \\
\hline & $\begin{array}{l}\text { Diploma in Nursing } \\
\text { (from Private NTS) }\end{array}$ & 51 & $40.8 \%$ \\
\hline & $\begin{array}{l}\text { Certificate in Nursing } \\
\text { (less than } 3 \text { Years) }\end{array}$ & 13 & $10.4 \%$ \\
\hline \multirow{4}{*}{$\begin{array}{l}\text { Clinical experience } \\
\text { as a nurse }\end{array}$} & Less than 5 Years & 71 & $56.8 \%$ \\
\hline & $6-10$ years & 26 & $20.8 \%$ \\
\hline & $11-20$ years & 15 & $12.8 \%$ \\
\hline & More than 20 years & 12 & $9.6 \%$ \\
\hline \multirow{3}{*}{ Level of knowledge } & Good & 66 & $52.8 \%$ \\
\hline & Average & 48 & $38.4 \%$ \\
\hline & Poor & 11 & $8.8 \%$ \\
\hline
\end{tabular}

Though stratified sampling was not applied, it was found that the $88 \%$ were female while $51 \%$ were unmarried irrespective of gender. Majority $(73.6 \%)$ had nursing diploma either from government $(33.8 \%)$ or private (40.8\%). Only $10 \%$ of the sample represented nursing certificate holders. Majority (57\%) of the sample had less than 5 years of clinical experience followed by $20.8 \%$ had $6-10$ years' experience. The level of knowledge on anthropometric measurement was found as good $(52.8 \%)>$ average $(38.4 \%)>$ poor $(8.8 \%)$. 


\section{Association between level of knowledge and demographic factors \\ Level of education \& level of knowledge}

Table 3.

Distribution between level of education and level of knowledge

\begin{tabular}{|c|c|c|c|c|c|}
\hline \multirow{2}{*}{\multicolumn{2}{|c|}{ Level of education }} & \multicolumn{3}{|c|}{ Level of knowledge } & \multirow{2}{*}{ Total } \\
\hline & & Good & Average & Poor & \\
\hline \multirow{2}{*}{$\begin{array}{l}\text { B. Sc. In } \\
\text { Nursing }\end{array}$} & Count & 20 & 0 & 0 & 20 \\
\hline & $\begin{array}{l}\text { \% within } \\
\text { Education }\end{array}$ & $100.0 \%$ & $0.0 \%$ & $0.0 \%$ & $100.0 \%$ \\
\hline \multirow{2}{*}{$\begin{array}{l}\text { Diploma } \\
\text { from } \\
\text { Government } \\
\text { NTS }\end{array}$} & Count & 22 & 15 & 4 & 41 \\
\hline & $\begin{array}{l}\% \text { within } \\
\text { Education }\end{array}$ & $53.7 \%$ & $36.6 \%$ & $9.8 \%$ & $100.0 \%$ \\
\hline \multirow{2}{*}{$\begin{array}{l}\text { Diploma } \\
\text { from Private } \\
\text { NTS }\end{array}$} & Count & 23 & 24 & 4 & 51 \\
\hline & $\begin{array}{l}\text { \% within } \\
\text { Education }\end{array}$ & $45.1 \%$ & $47.1 \%$ & $7.8 \%$ & $100.0 \%$ \\
\hline \multirow{2}{*}{$\begin{array}{l}\text { Nursing } \\
\text { Certificate }\end{array}$} & Count & 1 & 9 & 3 & 13 \\
\hline & $\begin{array}{l}\text { \% within } \\
\text { Education }\end{array}$ & $7.7 \%$ & $69.2 \%$ & $23.1 \%$ & $100.0 \%$ \\
\hline \multirow[b]{2}{*}{ Total } & Count & 66 & 48 & 11 & 125 \\
\hline & $\begin{array}{l}\% \text { within } \\
\text { Education }\end{array}$ & $52.8 \%$ & $38.4 \%$ & $8.8 \%$ & $100.0 \%$ \\
\hline \multicolumn{6}{|c|}{$\left(x_{6}^{2}=30.8, p=0.001\right)$} \\
\hline \multicolumn{3}{|c|}{$\begin{array}{l}\text { As chi-square test statistic is significant } \\
\text { ( } p<0.05 \text { ) in Table } 3 \text {, it can be concluded that } \\
\text { there is a significant association between level } \\
\text { of education and the level of knowledge of } \\
\text { the nurses. All the nurses having B Sc. Degree } \\
\text { has good knowledge. Among the diploma }\end{array}$} & \multicolumn{3}{|c|}{$\begin{array}{l}\text { holders the percentage of nurses having good } \\
\text { knowledge is almost the same as the percentage } \\
\text { of nurses having average knowledge. The } \\
\text { percentage of nurses having good knowledge } \\
\text { among those having certificate course is very } \\
\text { low. }\end{array}$} \\
\hline
\end{tabular}




\section{Level of knowledge and duration of clinical experience}

Table 4.

Distribution of level of knowledge and years of clinical experience

\begin{tabular}{|c|c|c|c|c|c|}
\hline \multirow{2}{*}{\multicolumn{2}{|c|}{ Years of experience }} & \multicolumn{3}{|c|}{ Level of knowledge } & \multirow{3}{*}{$\begin{array}{l}\text { Total } \\
68\end{array}$} \\
\hline & & \multirow{2}{*}{$\frac{\text { Good }}{43}$} & \multirow{2}{*}{$\begin{array}{l}\text { Average } \\
20\end{array}$} & \multirow{2}{*}{$\frac{\text { Poor }}{5}$} & \\
\hline & Count & & & & \\
\hline$<5$ years & $\begin{array}{l}\text { \% within } \\
\text { Experience }\end{array}$ & $63.2 \%$ & $29.4 \%$ & $7.4 \%$ & $100.0 \%$ \\
\hline \multirow[b]{2}{*}{$6-10$ years } & Count & 10 & 13 & 4 & 27 \\
\hline & $\begin{array}{l}\text { \% within } \\
\text { Experience }\end{array}$ & $37.0 \%$ & $48.1 \%$ & $14.8 \%$ & $100.0 \%$ \\
\hline \multirow[b]{2}{*}{$11-20$ years } & Count & 7 & 10 & 1 & 18 \\
\hline & $\begin{array}{l}\text { \% within } \\
\text { Experience }\end{array}$ & $38.9 \%$ & $55.6 \%$ & $5.6 \%$ & $100.0 \%$ \\
\hline \multirow{4}{*}{$>20$ years } & Count & 6 & 5 & 1 & 12 \\
\hline & $\begin{array}{l}\text { \% within } \\
\text { Experience }\end{array}$ & $50.0 \%$ & $41.7 \%$ & $8.3 \%$ & $100.0 \%$ \\
\hline & Count & 66 & 48 & 11 & 125 \\
\hline & $\begin{array}{l}\% \text { within } \\
\text { Experience }\end{array}$ & $52.8 \%$ & $38.4 \%$ & $8.8 \%$ & $100.0 \%$ \\
\hline
\end{tabular}

$\left(x_{6}^{2}=0.820, p=0.123\right)$

As chi-square test statistic is not significant $(p>0.05)$ in Table 4, it was found that there is no significant association between level of education and the years of experience of the nurses. Irrespective of the years of experience just above $50 \%$ of the nurses had a good knowledge followed by about $40 \%$ had an average knowledge. 


\section{Level of knowledge and gender}

Table 5.

Distribution of level of knowledge \& by gender

\begin{tabular}{llllll}
\hline \multirow{2}{*}{ Gender } & & \multicolumn{3}{c}{ Level of knowledge } & Total \\
\cline { 2 - 6 } & & good & average & poor & \\
\hline \multirow{2}{*}{ Male } & Count & 8 & 5 & 1 & 14 \\
\cline { 2 - 6 } & $\%$ within G & $57.1 \%$ & $35.7 \%$ & $7.1 \%$ & $100.0 \%$ \\
\hline \multirow{2}{*}{ Female } & Count & 58 & 43 & 10 & 111 \\
\cline { 2 - 6 } & $\%$ within G & $52.3 \%$ & $38.7 \%$ & $9.0 \%$ & $100.0 \%$ \\
\hline Total & & 66 & 48 & 11 & 124 \\
\hline \% within total & & $52.8 \%$ & $38.4 \%$ & $8.8 \%$ & $100.0 \%$ \\
\hline
\end{tabular}

$\left(x_{2}^{2}=0.135, p=0.923\right)$

As chi-square test statistic is not significant $(p>0.05)$ in Table 5, it indicates that there is no significant association between level of education and the years of experience of the nurses. Irrespective of gender 53\% have a good knowledge, $38 \%$ have an average knowledge and $9 \%$ have a poor knowledge.

\section{Level of practice in taking anthropometric measurements}

A majority of nurses (48\%) had stated that they were commonly taking measurements of weight while $9 \%$ had stated they have practiced of taking measurements of height. Furthermore, 37\% had stated that they have the practice of taking both measurements of weight and height. Only $6 \%$ of nurses had stated that they did not have the practice of taking height or weight measurements for nutritional assessments and it was identified that those nurses used to work in theatre. Though the nurses are spread in different wards, the impact of working section was not considered.

\section{Frequency of taking measurements}

The distribution of frequency of taking different measurements for nutritional assessments is shown in Table 6 . 
Table 6.

The percentage distribution different measurements for nutritional assessments.

\begin{tabular}{lllll}
\hline & $\begin{array}{l}\text { Often } \\
\mathrm{n}(\%)\end{array}$ & $\begin{array}{l}\text { Sometimes } \\
\mathrm{n}(\%)\end{array}$ & $\begin{array}{l}\text { Seldom } \\
\mathrm{n}(\%)\end{array}$ & $\begin{array}{l}\text { Never } \\
\mathrm{n}(\%)\end{array}$ \\
\hline Weight & $50(40)$ & $46(37)$ & $25(20)$ & $4(3)$ \\
\hline Height & $35(28)$ & $51(41)$ & $22(17.5)$ & $17(13.5)$ \\
\hline Waist Circumference & $0(0)$ & $09(8)$ & $40(32)$ & $76(61)$ \\
\hline Hip Circumference & $0(0)$ & $0(0)$ & $0(0)$ & $125(100)$ \\
\hline Head Circumference & $12(10)$ & $1(1)$ & $17(14)$ & $95(76)$ \\
\hline
\end{tabular}

Table 6 shows that the majority of nurses were practicing weighing often $(40 \%)$ and sometimes (37\%). The frequency of measuring height was found that the majority (41\%) had a practice of measuring height sometimes. A majority of participants had reported that they never practise measuring waist circumference $(61 \%)$ while all of them had reported the same for measuring Hip circumferences (100\%). patients.

\section{Practice of taking measurements of different types of patients}

Table 7.

Composition of the sample according to the group of patients whom they take anthropometric measurements mostly

\begin{tabular}{lcc}
\hline & Number of nurses $(\mathrm{N})$ & $(\%)$ \\
\hline Normal Adults & 96 & 76.8 \\
Children & 6 & 4.8 \\
Neonates & 11 & 8.8 \\
Bedridden patients & 7 & 5.6 \\
Patients with kidney diseases & 5 & 4.0 \\
Total & 125 & 100 \\
\hline
\end{tabular}


According to the table 7,77\% nurses have the practice of taking anthropometric measurements of normal adults while only $4 \%$ have the practice of taking measurements of kidney failure patients at the dialysis unit.

Type of constrain

Table 8.

Percentage distribution of discouraging factors to take anthropometric measurements in the hospital setup

\begin{tabular}{lll}
\hline Discouraging factor & $\mathrm{n}$ & $\%$ \\
\hline Lack of time & 41 & 32.8 \\
\hline Lack of resources & 32 & 25.6 \\
\hline As it is not important & 28 & 22.4 \\
\hline NDW & 24 & 19.2 \\
\hline Total & 125 & 100.0 \\
\hline
\end{tabular}

NDW - Not doing as a routing procedure in the ward
A majority (33\%) had indicated that lack of time as a discouraging factor to take anthropometric measurements followed by lack of resources $(26 \%)$.

\section{Level of attitudes in taking anthropometric measurements}

\section{Level of confidence}

It should be noted that almost all 125 nurses had expressed the importance of taking anthropometric measurements. The association between the confidence of taking anthropometric measurements (Yes or No) and anthropometric measurements is shown in Table 9. Missing values (neither y nor $\mathrm{n}$ ) were excluded for the analysis.

Table 9.

Association between level of confidence and type of measurement

\begin{tabular}{|c|c|c|c|}
\hline \multirow{2}{*}{ Measurement } & \multicolumn{2}{|c|}{ Confidence } & \multirow[t]{2}{*}{ Total } \\
\hline & Yes & No & \\
\hline \multirow{2}{*}{ Weight } & 116 & 8 & 124 \\
\hline & $93.5 \%$ & $6.5 \%$ & $100.0 \%$ \\
\hline \multirow{2}{*}{ Height } & 71 & 54 & 125 \\
\hline & $56.8 \%$ & $43.2 \%$ & $100.0 \%$ \\
\hline \multirow{2}{*}{$\begin{array}{l}\text { Waist } \\
\text { Circumference }\end{array}$} & 21 & 99 & 120 \\
\hline & $17.5 \%$ & $82.5 \%$ & $100.0 \%$ \\
\hline
\end{tabular}


Table 9 (Continued)

\begin{tabular}{llll}
\hline \multirow{2}{*}{ Hip Circumference } & 2 & 123 & 125 \\
\cline { 2 - 4 } & $1.6 \%$ & $98.4 \%$ & $100.0 \%$ \\
\hline $\begin{array}{l}\text { Head } \\
\text { Circumference }\end{array}$ & 76 & 49 & 125 \\
\hline \multirow{2}{*}{ Total } & $60.8 \%$ & $39.2 \%$ & $100.0 \%$ \\
\cline { 2 - 4 } & 286 & 333 & 619 \\
\hline
\end{tabular}

$\left(x_{4}^{2}=268.0, p=0.001\right)$

There is a significant association between the level of confidence and the type of measurement. The percentage of confidence for weight measurement $(93.5 \%)$ is significantly

higher than the percentage of confidence for taking other measurements. Almost all nurses are not confidence $(98.4 \%)$ in measuring hip circumference.

Table 10.

Composition of sample according to the factors associated with their attitudes towards anthropological assessments.

$\begin{array}{lcl}\text { Associated Factor } & \text { Yes } & \text { No } \\ & \mathrm{N}(\%) & \mathrm{N}(\%)\end{array}$

Feeling uncomfortable in taking measurements of body circumferences $95(76 \%) \quad 30(24 \%)$

Willingness to learn more about taking anthropological assessments $118(94 \%) \quad 7(6 \%)$

Having the attitude that the anthropological assessments should be included in the nursing curricula

Results revealed that the majority of the participants $(76 \%)$ feel uncomfortable in taking measurements of body circumferences. A majority $(56 \%)$ are not satisfied with the resources available in the hospital for taking anthropologic measurements. A large curricula. majority (94\%) were willing to learn more about taking anthropological assessments for nutritional assessments while $91 \%$ of nurses had an attitude of including more about anthropological assessments in the nursing 


\section{Discussion}

The purpose of this study is to identify the level of knowledge, practice and attitudes among nurses working in the selected teaching hospital . The current study showed levels of knowledge ranging as Good, Average or Poor. The majority of the participants had good knowledge $(53 \%)$ while $38 \%$ of nurses had average level of knowledge and $9 \%$ of the nurses had poor level of knowledge. This finding is inconsistent with previous findings of Bavelaar et al. (2008), \& Raja et al., (2008) as they have found that lack of knowledge as one of the most prominent factors limiting the systematic measurement of body weight and height in hospitalized patients.

The findings of the study reflect that most of the nurses have practice of measuring weight. But the majority of nurses are not aware about the weight measurement. Lin and Perry (2007) have found that height is most commonly used as a nutritional index with children. These findings are similar to the findings of this study as all of nurses working in paediatric ward have good practice of measuring height of children for nutritional assessment. Alison et al. (2009) states that most health care professionals do not receive any specific training in how to carry out waist circumference measurement. Similar to that, present study has found that majority of participants have not had training on waist circumference and hip circumference. This study found that nurses seldom use nutritional screening tools and nutritional guidelines for assessing patients. This finding is in agreement with the study of Persenius et al. in 2008 as they reported that nutritional assessment/ screening tools and nutritional guidelines were seldom used for nutritional assessments by the majority of nurses in their study. In the present study a majority has stated that "lack of time" as the major cause of factors discouraging to take anthropometric measurements. This is consistent with other studies by Bavelaar et al. (2008) and Raja et al. (2008) as they have cited too much work to be accomplished by nurses within short time during their working hours. Majority of participants had positive attitudes towards taking anthropometric measurements and majority of nurses (94\%) are willing to learn more about nutritional assessments. This Finding is consistent with the study done by Kim and Choue (2009) to detect knowledge of nutritional assessment in Korean nurses as they have found those Korean nurses had a high desire to receive nutritional information.

\section{Conclusions and Recommendations}

Based on the results of data analyses, the following conclusions and recommendations can be given.

\section{Conclusions}

The majority of nurses have knowledge about anthropometric measurements for nutritional assessments. Among the Bachelor of Nursing, graduates have a significantly higher level of knowledge comparing to diploma holders from both government and private Nurses. Knowledge, Practice, and Attitudes have not been significantly associated with sociodemographic factors such as sex, marital status, and years of experience. The percentage of confidence for weight measurement $(93.5 \%)$ is significantly higher than the percentage of confidence for taking other measurements. Almost all nurses (98.4\%) are not confident 
in taking measurements of hip circumference. Lack of time, lack of resources are the two main constraints to take anthropometric measurements and the nurses have positive attitudes to learn about anthropometric measurements for nutritional assessments.

\section{Recommendations}

Findings will help to adopt new teaching and learning strategies in nursing education to improve the level of knowledge of nurses. Due to various constraints such as manpower, funds and time, this study was limited to 125 participants in one hospital. Thus, it is necessary to extend this study for few other hospitals. All the practices associated with taking anthropometric measurements were not assessed in this study. It should be looked into more deeply in order to obtain better results. Inclusion of nurses working on part time basis will increase the validity of the findings.

\section{References}

Bart, G., Eric, F., Joost, W., \& Dirk, Y. (2011). Nurses estimating body weight and height to screen for malnutrition. The European e-journal of clinical nutrition and metabolism, http://www.elsevier. com/locate/clnu viewed on 02 May 2017.

Bavelaar, J. W., Otter, C. D., van Bodegraven, A. A., Thijs, A., van Bokhorst \& van der Schueren, M. A. E. (2008). Diagnosis and treatment of (disease-related) in-hospital malnutrition. Clinical Nutrition 2008; 27:431e8.

Bowring, A. L., Peeters, A., Poli, R. F., Lim, M. S. C., Gouillou, M. \& Hellard,
M. (2010). Measuring the accuracy of self-reported height and weight in a community-based sample of young people, British Journal of Nutrition, page 1 of 7 doi:10.1017/ S0007114510004563.

Fuchs, D. J. G., Frances, A. \& La-Pierre, (2014). National Kidney Foundation Primer on Kidney Diseases (Sixth Edition), Retrieved from:https://www. sciencedirect.com/topics/medicineand-dentistry/anthropometry.

Hayes, A. J., Kortt, M. A., Clarke, P. M., \& Brandrup, J. D. (2008). Estimating equations to correct self-reported height and weight: implications for prevalence of overweight and obesity in Australia. Australian and Newzealnd Journal of Public Health.

Health and Nutrition Examination Survey, (2004). Anthropometry procedures manual, viewed on 21 April 2017 https://www.cdc.gov/nchs/data/nhanes/ nhanes_03_04/BM.pdf.

Jayawardena, R., Ranasinghe, P., Wijayabandara, M., Hills, A. P. \& Misra, A. (2017). Nutrition Transition and Obesity Among Teenagers and Young Adults in South Asia, Journal of Current Diabetes Reviews, Volume 13 , Issue 5, 2017.

Krul, A. J., Daanen, H. A. M. \& Choi, J. (2010). Self-reported and measured weight, height and body mass index (BMI) in Italy, the Netherlands and North America. Eur Jurnal of Public Health 21: 414-419. viewed on 10 May 2017 https://journals.plos.org/ plosone/article?id=10.1371/journal. pone.0054386\#. 
Louay, L. (2017). Nutritional knowledge assessment of Syrian university students Students' Publications, viewed on 8 January 2018 http://www.jscisociety. com.

Mokdad, A. H., Ford, E. S., Bowman, B. A., Dietz WH, Vinicor F, Bales VS, \& Marks, J. S. (2001). Prevalence of obesity, diabetes, and obesity-related health risk factors among US adults, Available at: <https://www.ncbi.nlm. nih.gov/pubmed/12503980 $>$ viewed on 4 September 2017.

Monde, M. (2011). The KAP Survey Model (Knowledge, Attitudes, and Practices), Caring Capacity \& Practices, Health Care Retrieved from: http://www. medecinsdumonde.org/Outils/Nouscontacte.

Nanayakkara, D. (1998). Anthropometric measurements of Sri Lankan newborns, The Ceylon Journal of Medical Science 1998; 41:01-06, Available at: https://cjms.sljol.info/articles/ abstract/10.4038/cjms.v41i1.4891/.

Sarani, H., Balouchi, A., Masinaeinezhad, N. \& Ebrahimitabs, E. (2014). Knowledge, Attitude and Practice of Nurses about Standard Precautions for HospitalAcquired Infection in Teaching Hospitals Affiliated to Zabol University of Medical Sciences, Retrieved from: $<$ https:/www.ncbi.nlm.nih.gov/pmc/ articles/PMC4804055> Viewed on July 2017.

Shiely, F., Hayes, K., Ivan, J., Perry, C., Kelleher, C. (2013). Height and Weight
Bias: The Influence of Time, PLOS Publications, Available at: https:// journals.plos.org/plosone/article/ file?id=10.1371/journal.pone.0054386.

Valla, F. V., Ford-Chessel, C., Meyer, R., Berthiller, J., Dupenloup, C., FollinArbelet, N., Hubert, A., Javouhey, E. \& Peretti, N. (2013). A training program for anthropometric measurements by a dedicated nutrition support team improves nutritional status assessment of the critically ill child, Students' Publications, Retrieved from: https://www.ncbi.nlm. nih.gov/pubmed/25607742.

World health Organization, World health Statistics, (2015) Retrieved from: https://www.who.int/docs/defaultsource/gho-documents/worldhealth-statistic-reports/world-healthstatistics-2015.pdf.

Zhu1, D. Q., Ian, J., Norman, Alison, E. \& While, (2013). Nurses' self-efficacy and practices relating to weight management of adult patients: a path analysis International Journal of Behavioral Nutrition and Physical Activity, Retrieved from: http://www. ijbnpa.org/content/10/1/131 viewed on June 2017.

Zhu, S. K., Wang, Z. M., Heshka, S. et al. (2002), Waist circumference and obesity-associated risk factors among whites in the third National Health and Nutrition Examination Survey: Clinical action thresholds. American Journal of Clinical Nutrition 2002;76 (4):743749. 